\title{
Selection from fixed term to permanent employment: prospective study on health, job satisfaction, and behavioural risks
}

\author{
M Virtanen, M Kivimäki, M Elovainio, J Vahtera
}

See end of article for authors' affiliations

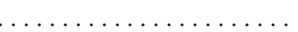

Correspondence to: $M$ Virtanen, Finnish Institute of Occupational Health, Department of Psychology, Topeliuksenkatu 41 a A, FIN-00250 Helsinki, Finland;

marianna.virtanen@ occuphealth.fi

Accepted for publication 5 January 2002

\begin{abstract}
Study objective: To examine health, job satisfaction, and behavioural risks as antecedents of selection from fixed term to permanent employment.

Design: Prospective cohort study of change in employment contract during a two year period. Self reported health, recorded sickness absence, job satisfaction, behavioural risks, demographics, and occupational characteristics were assessed at baseline.

Setting: Hospital staff in two Finnish hospital districts.

Participants: A cohort of 526 hospital employees (54 men, 472 women) aged 20 to 58 years with a fixed term job contract at baseline.

Main results: During the follow up period, 137 became permanently employed. Men, employees in higher positions, full time workers, and those with five to eight years in the employ of the hospital were more likely to become permanently employed. After adjusting for these factors, obtaining a permanent job contract was predicted by self rated good health (odds ratio (OR) $3.90 ; 95 \%$ confidence intervals (Cl) 1.34 to 11.36 ), non-caseness of psychological distress (OR 1.80; $95 \% \mathrm{Cl} 1.01$ to 3.20), high job satisfaction (OR 1.86; $\mathrm{Cl} 1.17$ to 2.94), and non-sedentary life style (OR 2.64; $\mathrm{Cl} 1.29$ to 5.41 ), compared with the rest of the cohort.

Conclusions: Investigation of fixed term employees yields new information about selective mechanisms in employment mobility. Good health seems to promote the chances for a fixed term employee to reach a better labour market status. These results correspond to earlier research on selective mechanisms in other forms of employment mobility and provide a partial explanation for the socioeconomic gradient of health.
\end{abstract}

R apid changes in worklife have led to various forms of precarious employment, including fixed term, temporary, and part time employment. In the European Union (EU), precarious employment accounts for $12 \%-15 \%$ of paid employment. ${ }^{12}$ The labour force seems to differ according to a centre-periphery structure, in which a "core" consists of nearly $70 \%$ of workforce, a barrier of contingent (fixed term and temporary) workers of about $12 \%$, self employed $10 \%$, and unemployed $10 \%{ }^{1}$ In the context of a differentiated labour market and job competition, the issue of health selection in labour force mobility from an insecure employment status towards the more secure core has been proposed. ${ }^{3}$

Health inequalities in the social and occupational hierarchy is a recognised phenomenon explained in part by health selection, a process in which healthy people are more likely to move up the hierarchy while unhealthy people move down. ${ }^{4}$ Research on labour force mobility has indicated that health selection is manifest from employment to unemployment, ${ }^{5-9}$ from unemployment to re-employment, ${ }^{10}$ in educational achievement, ${ }^{11}{ }^{12}$ and in occupational mobility. ${ }^{13}$ To date, studies have not investigated the role of health selection from contingent employment to permanent employment. Bauer and Truxillo $^{14}$ found in their study of temporary to permanent clerical workers that individual characteristics, such as tolerance of ambiguity and role adjustment, were related to perceived stress during the job trial period and success at being hired permanently.

A consistent working environment, the use of both self reported and registered data, and the possibility to follow up the same subjects in a prospective study design provided us with an opportunity to examine health selection between fixed term and permanent employment. The study aims, firstly, to assess whether health selection exists from fixed term to permanent employment and secondly, to investigate what other demographic and occupational characteristics predict an employee's success at being hired permanently.

\section{METHODS}

\section{Study context}

In the public health care sector in Finland between 1990 and 1995, the proportion of employees with a fixed term employment contract rose from $15 \%$ to $21 \%{ }^{15}$ At the same time the unemployment rate rose from $3 \%$ to $15 \%$ being $11 \%$ at the time of the study, indicating competition for jobs. ${ }^{16}$ Fixed term employment as a voluntary choice in the public health care sector was rare: $85 \%-88 \%$ of the fixed term employees reported having this form job contract because few permanent posts were available and open. ${ }^{15}$

\section{Participants}

This study was carried out in two hospital districts (VarsinaisSuomi and Kanta-Häme) participating in a project "Work and Health in Finnish Hospital Personnel" coordinated by the Finnish Institute of Occupational Health. There were one university teaching hospital, one central hospital, and eight regional hospitals providing specialised health care for 614000 inhabitants ( $12 \%$ of the total Finnish population).

At the beginning of 1998, a questionnaire on employment contract, health, job satisfaction, behavioural risks, and other variables was sent to all 7375 employees to be filled in (1156 men, 6219 women). Of these employees, 5668 (679 men, 4989 women) responded to the questionnaire (response rate $77 \%$ ). A fixed term job contract was reported by 1203 (21\%). Two years 
later, a follow up questionnaire on current employment contract was sent to those 712 (59\%) of the baseline fixed term participants still employed at the organisation. Of these, 532 (75\%) completed the follow up questionnaire. Information on job contracts was missing in six responses, which were excluded. The remaining 526 respondents ( 54 men, 472 women) of the follow up survey formed the final cohort of this study.

\section{Measures}

The information on the participants' job contract was obtained in both surveys through the following question: "What kind of a work contract do you have?" (permanent; substitute or fixed term; subsidised-that is, employed by social fund). Only respondents reporting being substitutes or fixed term employees at baseline were taken into account in this study. Based on a categorisation of work status at baseline and follow up, the cohort comprised two groups of employees: (1) baseline fixed term and follow up fixed term employees, (2) baseline fixed term and follow up permanent employees. Health was measured at the baseline by the following three indicators: self rated health, recorded sickness absence; and psychological distress. Self rated health is a single item measure in which the respondents provide an overall assessment of their health on a 5 point scale $(1=$ poor, $2=$ fairly poor, $3=$ average, $4=$ fairly good, $5=$ good). The scale was dichotomised by grouping response scores $1-3$ as a category of poor or average self rated health and scores 4 and 5 as good self rated health. This scale categorisation is widely used in medical, epidemiological, and health psychological research providing to be a powerful predictor of mortality and morbidity. ${ }^{17-20}$

All of the participants' sickness absences between 1 January 1996 and 31 December 1997 were obtained from the employers' registers documenting and listing the beginning and end dates of every sick leave period for each employee. In accordance with existing regulations, each sick leave certificate, irrespective of the place of issue, must be forwarded to these registers. Maternity leaves and absences due to caring for a sick child are not covered by sickness absences. Overlapping and duplicated sick leaves were corrected for. Two year sickness absences were calculated as follows: number of sickness absence days per number of contracted days worked between l January 1996 and 31 December 1997. The number of contracted days represented "days at risk", from which the number of days absent from work for reasons other than sickness was subtracted. ${ }^{21}{ }^{22}$ The sickness absence distribution of values was divided into quartiles and dichotomised, the highest quartile against the other three quartiles.

Psychological distress was measured by the 12 item version of Goldberg's ${ }^{23}$ General Health Questionnaire (GHQ-12), producing results comparable to the longer versions of GHQ. ${ }^{24} 25$ The respondent rates each of the 12 items on symptoms of psychological distress according to how it was experienced $(0=$ not at all, $1=$ the same as usual, $2=$ rather more than usual or $3=$ much more than usual) over the previous few weeks. In the current sample, GHQ-12 was used as a dichotomous measure in which persons who rated 2 or 3 in at least four items of the total measure were identified as cases.

Job satisfaction was assessed by an overall measure of satisfaction consisting of 12 items from Hackman and Oldham's ${ }^{26}$ Job Diagnostic Survey. This scale assesses satisfaction with pay, coworkers, supervision, and personal growth. A 7 point scale (from $1=$ extremely dissatisfied to $7=$ extremely satisfied) was used to rate the items. Coefficient $\alpha$ was $r=0.86$. The distribution of a simple sum was divided into quartiles and dichotomised: the highest quartile compared with the other three quartiles.

Behavioural risks were measured in standard ways. Smoking was assessed by a question about whether the respondent was a current smoker or not. The rate of absolute alcohol in grams consumed in an average week was based on an alcohol questionnaire by Kaprio and others. ${ }^{27}$ The measure was dichotomised using cut off points for heavy alcohol use (for men $>280$ g per week, for women $>190$ g per week). Sedentary lifestyle was indicated by leisure time physical activity corresponding to under half an hour of fast walking per week. ${ }^{28}$ Body mass index was calculated from self reported information on participants' weight and height, and dichotomised by BMI value 30 .

Other variables included the following demographic and occupational characteristics: sex, age, organisational tenure, occupational title, income, and hours of work. Of these, sex, age, and occupational title were obtained from the employers' registers. Occupational titles, expressed as five digit Statistics Finland codes, were used to link information on income to the dataset. Average monthly income figures, calculated separately for men and women by occupational title, were obtained from Statistics Finland. Occupational titles were divided into three occupational groups: doctors, nurses, and other personnel (maintenance, cleaning, administrative, clerical, kitchen staff, etc). Organisational tenure (number of years that the respondent had worked for the present employer) and hours of work (full time or part time work) were based on the survey responses.

\section{Data analysis}

To examine sample attrition, we compared the employees who stayed in the organisations with those who left. We calculated descriptive statistics for each of the variables and assessed the difference between groups by $\chi^{2}$ tests and univariate analysis of variance. To further examine the connections of income, sickness absence, and job satisfaction with drop out, the odds ratios of leaving were calculated for these variables. Tetrachoric correlations were used to assess the relations between the health indicators, job satisfaction, and behavioural risks.

Hierarchical logistic regression models were used to calculate odds ratios of fixed term employees to become permanently employed for health, job satisfaction, and behavioural risks. Odds ratios and their 95\% confidence intervals (CI) were adjusted for sex, organisational tenure, income, and hours of work. Health, job satisfaction, and behavioural risks are inter-related but theoretically distinct concepts. In the fully adjusted models, the effect of health indicators on achieving a permanent job contract was additionally adjusted for job satisfaction and behavioural risks. A corresponding strategy was applied for modelling the effects of job satisfaction (adjusted for health indicators and behavioural risks) and behavioural risks (adjusted for job satisfaction and health indicators). Although other indicators of the same concept were not adjusted for in the same model, the fully adjusted models are likely to provide conservative estimates. The SPSS 9.0 program package was applied in all analyses.

\section{Ethical approval}

Approval of the ethics committee of the Finnish Institute of Occupational Health was obtained for this study.

\section{RESULTS}

\section{Response rates and attrition}

Table 1 shows the baseline characteristics for all 1203 fixed term respondents in the first survey, and separately for those $712(59 \%)$ employees who stayed at the hospital as well as those 491 (41\%) employees who left or lost their jobs before the follow up survey. The comparisons were made between those who stayed and those who left. The leavers were more often younger employees, had a shorter tenure, were less often nurses, had a lower monthly income, worked more often part time, had a higher rate of sickness absence, and were less satisfied with their jobs than those who stayed in the organisation. The leavers did not differ from those who stayed in terms of sex, self rated health, psychological distress, and behavioural risks. 
Table 1 Baseline characteristics of the participants with a fixed term job contract at baseline

\begin{tabular}{|c|c|c|c|c|}
\hline \multirow[b]{2}{*}{ Characteristics at baseline } & \multirow[b]{2}{*}{$\begin{array}{l}\text { All }(n=1203) \\
n(\%)\end{array}$} & \multicolumn{2}{|c|}{ Employment at follow up } & \multirow[b]{2}{*}{$\begin{array}{l}\text { p for } \\
\text { difference }\end{array}$} \\
\hline & & $\begin{array}{l}\text { Stayer }(\mathrm{n}=712) \\
\mathrm{n}(\%)\end{array}$ & $\begin{array}{l}\text { Leaver }(n=491) \\
n(\%)\end{array}$ & \\
\hline Sex & & & & 0.283 \\
\hline Men & $147(12)$ & $93(13)$ & $54(11)$ & \\
\hline Women & $1056(88)$ & $619(87)$ & $437(89)$ & \\
\hline Age (years) & & & & $<0.001$ \\
\hline $19-29$ & $353(29)$ & $169(24)$ & $184(37)$ & \\
\hline $30-39$ & $471(39)$ & $276(39)$ & $195(40)$ & \\
\hline $40-49$ & $259(22)$ & $180(25)$ & $79(16)$ & \\
\hline $50-58$ & $120(10)$ & 87 (12) & $33(7)$ & \\
\hline Organisational tenure (years) & & & & $<0.001$ \\
\hline$<1$ & $118(10)$ & $50(7)$ & $68(14)$ & \\
\hline $1-4$ & $646(55)$ & $359(52)$ & $287(60)$ & \\
\hline $5-8$ & $253(22)$ & $167(24)$ & $86(18)$ & \\
\hline$>8$ & $157(13)$ & $120(17)$ & $37(8)$ & \\
\hline Occupational group & & & & 0.001 \\
\hline Doctors & $128(11)$ & $72(10)$ & $56(12)$ & \\
\hline Nurses & 768 (64) & $485(68)$ & $283(58)$ & \\
\hline Others (eg, maintenance, cleaning) & $302(25)$ & $154(22)$ & $148(30)$ & \\
\hline Income ${ }^{*}$ & & & & 0.002 \\
\hline 1st (low) & $\begin{array}{l}603(51) \\
580(49)\end{array}$ & $\begin{array}{l}332(47) \\
370(53)\end{array}$ & $271(56)$ & \\
\hline $\begin{array}{l}\text { 2nd (high) } \\
\text { Hours of work }\end{array}$ & $580(49)$ & $370(53)$ & $210(44)$ & $<0.001$ \\
\hline Full time & $998(85)$ & $621(89)$ & 377 (79) & \\
\hline Part time & $176(15)$ & $77(11)$ & $99(21)$ & \\
\hline Self rated health & & & & 0.806 \\
\hline Poor / average & $118(10)$ & $71(10)$ & $47(10)$ & \\
\hline Good & $1078(90)$ & $636(90)$ & $442(90)$ & \\
\hline Sickness absence (quartiles) & & & & 0.015 \\
\hline Low/moderate (1 st to 3rd) & $574(72)$ & $375(75)$ & $199(67)$ & \\
\hline High (4th) & $218(28)$ & $122(25)$ & $96(33)$ & \\
\hline Psychological distress & & & & 0.321 \\
\hline Non-case & 935 (79) & $560(80)$ & $375(78)$ & \\
\hline Case & $243(21)$ & $137(20)$ & $106(22)$ & \\
\hline Job satisfaction (quartiles) & & & & 0.021 \\
\hline Low/moderate ( 1 st to $3 \mathrm{rd}$ ) & $891(75)$ & $510(72)$ & $381(78)$ & \\
\hline High (4th) & $304(25)$ & $197(28)$ & $107(22)$ & \\
\hline Smoking & & & & 0.227 \\
\hline Non-smoker & $970(84)$ & $561(83)$ & $409(86)$ & \\
\hline Current smoker & $182(16)$ & $114(17)$ & $68(14)$ & \\
\hline Alcohol consumption $\dagger$ & & & & 0.162 \\
\hline No/moderate & $1097(93)$ & $641(92)$ & $456(94)$ & \\
\hline High & $83(7)$ & $55(8)$ & $28(6)$ & \\
\hline Physical activity & & & & 0.386 \\
\hline Sedentary & $176(15)$ & $109(16)$ & $67(14)$ & \\
\hline Non-sedentary & $1006(85)$ & 588 (84) & $418(86)$ & \\
\hline Body mass index $\left(\mathrm{kg} / \mathrm{m}^{2}\right)$ & & & & 0.954 \\
\hline$\leqslant 30$ & $1093(95)$ & $641(95)$ & $452(95)$ & \\
\hline$>30$ & $61(5)$ & $36(5)$ & $25(5)$ & \\
\hline
\end{tabular}

Table 2 Tetrachoric correlations between health indicators, job satisfaction, and behavioural risks

\begin{tabular}{|c|c|c|c|c|c|c|c|}
\hline Variable & 1 & 2 & 3 & 4 & 5 & 6 & 7 \\
\hline \multicolumn{8}{|l|}{1 Self rated health (poor/average $v$ good) } \\
\hline 2 Sickness absence (high $v$ lower) & $0.33 * * *$ & & & & & & \\
\hline 3 Psychological distress (case $v$ non-case) & $0.24^{*}$ & 0.04 & & & & & \\
\hline 4 Job satisfaction (lower $v$ high) & $0.25^{*}$ & 0.31 ** & $0.38 * * *$ & & & & \\
\hline 5 Smoking (current smoker $v$ non-smoker) & -0.02 & 0.19 & $0.22^{*}$ & 0.17 & & & \\
\hline 6 Alcohol consumptiont (high $v$ low/moderate) & 0.14 & 0.05 & $0.23^{*}$ & -0.12 & 0.30 ** & & \\
\hline 7 Physical activity (sedentary $v$ non-sedentary) & $0.22 *$ & 0.08 & -0.07 & 0.17 & -0.05 & -0.02 & \\
\hline 8 Body mass index (overweight $v$ not) $\ddagger$ & $0.30 *$ & 0.21 & -0.10 & 0.15 & 0.13 & 0.18 & 0.32 ** \\
\hline
\end{tabular}

To further examine the connections of income, sickness absence, and job satisfaction with drop out, we constructed age adjusted hierarchical logistic regression models. The odds ratio of leaving in the lower income group, compared with the higher income group, was 1.70 (95\% CI 1.33 to 2.17 ). Corresponding odds ratio for high sickness absence versus lower sickness absence was 1.59 ( 1.14 to 2.22 ), and lower ver- sus high job satisfaction 1.31 (95\% CI 0.99 to 1.72 ). Then we put sickness absence and income as predictors into the same model. The odds ratios of dropping out for low income and high sickness absence were 1.63 (95\% CI 1.19 to 2.22 ) and 1.49 (95\% CI 1.06, 2.09), respectively. Thus, both income and sickness absence had an independent effect on dropping out. To assess whether low income combined with poor health is a 
Table 3 Odds ratio of fixed term to permanent employment status by demographic and occupational characteristics at baseline

\begin{tabular}{|c|c|c|c|}
\hline Characteristics & Number & Odds ratio $(95 \% \mathrm{Cl})$ & $\mathrm{p}$ Value \\
\hline \multicolumn{4}{|l|}{ Sex } \\
\hline Women & 472 & 1.0 & \\
\hline Men & 54 & 2.13 (1.19 to 3.82$)$ & 0.011 \\
\hline \multicolumn{4}{|l|}{ Age (years) } \\
\hline $20-29$ & 126 & 1.0 & \\
\hline $30-39$ & 201 & $1.36(0.82$ to 2.27$)$ & 0.235 \\
\hline $40-49$ & 136 & $1.07(0.61$ to 1.88$)$ & 0.823 \\
\hline $50-58$ & 63 & $0.83(0.40$ to 1.74$)$ & 0.624 \\
\hline \multicolumn{4}{|l|}{ Organisational tenure (years) } \\
\hline$<1$ & 33 & 1.0 & \\
\hline $1-4$ & 259 & $3.82(1.14$ to 12.87$)$ & 0.030 \\
\hline $5-8$ & 131 & $3.91(1.13$ to 13.54$)$ & 0.032 \\
\hline$>8$ & 95 & $2.99(0.84$ to 10.71$)$ & 0.092 \\
\hline \multicolumn{4}{|l|}{ Occupational group } \\
\hline Others (eg, maintenance, cleaning) & 99 & 1.0 & \\
\hline Doctors & 41 & $1.54(0.66$ to 3.62$)$ & 0.318 \\
\hline Nurses & 386 & $1.61(0.93$ to 2.79$)$ & 0.086 \\
\hline \multicolumn{4}{|l|}{ Income* } \\
\hline lst (low) & 246 & 1.0 & \\
\hline 2nd (high) & 274 & 1.84 (1.23 to 2.75$)$ & 0.003 \\
\hline \multicolumn{4}{|l|}{ Hours of work } \\
\hline Part time & 57 & 1.0 & \\
\hline Full time & 459 & $5.29(1.88$ to 14.91$)$ & 0.002 \\
\hline
\end{tabular}

\begin{tabular}{|c|c|c|c|c|c|}
\hline & Number & $\begin{array}{l}\text { Unadjusted } \\
\text { Odds ratio }(95 \% \mathrm{Cl})\end{array}$ & $\mathrm{p}$ Value & $\begin{array}{l}\text { Adjusted* } \\
\text { Odds ratio }(95 \% \mathrm{Cl})\end{array}$ & $\mathrm{p}$ Value \\
\hline \multicolumn{6}{|l|}{ Self rated health } \\
\hline Poor/average & 52 & 1.0 & & 1.0 & \\
\hline Good & 471 & 2.85 (1.19 to 6.84$)$ & 0.019 & $3.90(1.34$ to 11.36$)$ & 0.013 \\
\hline \multicolumn{6}{|l|}{ Sickness absence (quartiles) } \\
\hline High (4th) & 93 & 1.0 & & 1.0 & \\
\hline Low/moderate (1 st to $3 \mathrm{rd}$ ) & 279 & $1.59(0.90$ to 2.81$)$ & 0.107 & $1.41(0.77$ to 2.58$)$ & 0.272 \\
\hline \multicolumn{6}{|l|}{ Psychological distress } \\
\hline Case & 103 & 1.0 & & 1.0 & \\
\hline Non-case & 419 & $1.27(0.76$ to 2.12$)$ & 0.362 & $1.80(1.01$ to 3.20$)$ & 0.048 \\
\hline \multicolumn{6}{|l|}{ Job satisfaction (quartiles) } \\
\hline Low/moderate (1 st to 3rd) & 137 & 1.0 & & 1.0 & \\
\hline High (4th) & 387 & $1.61(1.05$ to 2.48$)$ & 0.028 & $1.86(1.17$ to 2.94$)$ & 0.008 \\
\hline \multicolumn{6}{|l|}{ Smoking } \\
\hline Current smoker & 87 & 1.0 & & 1.0 & \\
\hline Non-smoker & 417 & $1.57(0.89$ to 2.78$)$ & 0.123 & $1.53(0.83$ to 2.83$)$ & 0.178 \\
\hline \multicolumn{6}{|l|}{ Alcohol consumption $\dagger$} \\
\hline High & 39 & 1.0 & & 1.0 & \\
\hline No/moderate & 481 & $1.17(0.54$ to 2.53$)$ & 0.690 & $1.16(0.50$ to 2.71$)$ & 0.735 \\
\hline \multicolumn{6}{|l|}{ Physical activity } \\
\hline Sedentary & 83 & 1.0 & & 1.0 & \\
\hline Non-sedentary & 436 & 2.54 (1.30 to 4.95$)$ & 0.006 & 2.64 (1.29 to 5.41$)$ & 0.008 \\
\hline \multicolumn{6}{|l|}{ Body mass index $\left(\mathrm{kg} / \mathrm{m}^{2}\right)$} \\
\hline$>30$ & 29 & 1.0 & & 1.0 & \\
\hline$\leqslant 30$ & 438 & 5.21 (1.22 to 22.24$)$ & 0.026 & 3.83 (0.86 to 17.02$)$ & 0.078 \\
\hline
\end{tabular}

risk of dropping out, we calculated the age adjusted interaction models between the health indicators, income and drop out. No interactions were found between self rated health and income $(p=0.747)$, between psychological distress and income $(p=0.084)$ or between sickness absence and income $(\mathrm{p}=0.764)$.

Of the 1203 respondents in the first survey, 712 were still employed, 526 with information on job contract also responded to the second one. Of these, $54(10 \%)$ were men and $472(90 \%)$ women, their mean age being 37.0 (SD 8.7) years and mean organisational tenure 5.3 (SD 5.1) years. A total of $459(89 \%)$ worked full time, while $57(11 \%)$ had a part time job (missing information in 10 responses). There were 41 (8\%) physicians, $386(73 \%)$ nurses, and 99 (19\%) other staff in cleaning, maintenance and administrative functions.
The 526 respondents and 180 non-respondents in the second survey did not differ from each other in terms of mean age (37.0 $v 37.1, F=0.03, \mathrm{p}=0.860)$, although women $(90 \% v$ $78 \%, F=16.0, \mathrm{p}<0.001)$ and employees with a lower monthly salary €1847.50 $v € 1958.50, F=4.21, \mathrm{p}<0.05)$ were overrepresented in the respondents.

\section{Correlation between health indicators, job satisfaction,} and behavioural risks

Table 2 shows that the health indicators were inter-related with one exception: sickness absence did not correlate with psychological distress. Job satisfaction was related to all the health indicators, especially to psychological distress. The correlations between behavioural risks and health indicators were moderate or non-significant. Smoking was associated 
with high alcohol consumption, and overweight was associated with a sedentary lifestyle.

\section{Predictors of permanent employment}

A total of 137 employees (26\%) of the cohort had received a permanent job contract by the follow up survey. Male employees, those with a tenure of one to eight years, those with higher monthly income, and those who worked full time had a greater chance to become permanently employed than the others (table 3 ).

Self rated good health, high job satisfaction, non-sedentary lifestyle, and a body mass not exceeding $30 \mathrm{~kg} / \mathrm{m}^{2}$ predicted attaining a permanent position (table 4). To exclude the effect of other predictors of selection and to assess the effect of health, job satisfaction, and behavioural risks on employee mobility, we adjusted the odds ratios for sex, organisational tenure, income, and hours of work. Employees with self rated good health had almost four times greater odds to become permanently employed than did employees with self rated average or poor health. The corresponding odds ratio between non-cases and cases of psychological distress was 1.8 and between highly satisfied and less satisfied workers 1.9. Additionally, employees whose lifestyle was non-sedentary had 2.6 times greater odds to become permanently employed than did their colleagues leading a sedentary lifestyle.

In the fully adjusted models (not shown in the tables), the adjustments were first made for sex, organisational tenure, income, and hours of work. Four separate hierarchical logistic regression models were constructed: in the models 1 and 2 the effects of health indicators (self rated health and psychological distress) were adjusted for job satisfaction and physical activity; in the model 3 the effect of job satisfaction was adjusted for health indicators and physical activity, and; in the model 4 the effect of physical activity was adjusted for job satisfaction and health indicators. The odds ratio (95\% CI) of permanent employment was 3.41 ( 1.16 to 9.99 ) for self rated good health; 1.67 (0.92 to 3.02) for non-caseness of psychological distress; 1.56 (0.96 to 2.51) for high job satisfaction; and 2.44 ( 1.18 to 5.04) for non-sedentary lifestyle.

\section{DISCUSSION}

The objective of this study was to assess whether health selection occurs between fixed term and permanent employment and to investigate what other demographic and occupational characteristics predict permanent employment. Our findings on hospital personnel suggest that health selection indeed does operate in the mobility of employees from fixed term to permanent employment status. Specifically, obtaining a permanent job was more likely for employees with good self rated and psychological health, a non-sedentary lifestyle, and high job satisfaction.

\section{Health selection}

These results are in line with earlier studies on health selection regarding employment status. ${ }^{5-10}$ Health selection has been shown to operate during the critical points earlier in the course of life, for example, in success at school. ${ }^{11}{ }^{12}$ Our results on health selection in gaining a place in the core of the labour market further support the suggested health selection as a continuous process with certain critical junctures during one's life course. West has gone so far as to propose that a major part of health selection may occur in the period between entry into the labour market and the achievement of a stable occupation. $^{29}$

Psychological resources may contribute to employees' success in the competition for permanent jobs. ${ }^{14}$ Current results indicate that self rated good health and low psychological distress are important predictors of permanent employment. Job insecurity has commonly been experienced among fixed term employees ${ }^{30-32}$ and been a significant

\section{Key points}

- Research has shown health selection in relation to unemployment, re-employment, educational achievement, and promotion.

- Health selection also seems to operate in mobility from fixed term to permanent employment.

- Among fixed term employees, self rated good health and a non-sedentary lifestyle seems to be strong predictors of receiving permanent employment.

stressor generating psychological distress, ${ }^{33-35}$ other health problems, ${ }^{34-36}$ and increased sickness absence. ${ }^{21} 223738$ Thus, fixed term employees with good psychological resources may be better able to tolerate stress caused by job insecurity and other potential detriments in fixed term jobs.

In addition to direct selection, our results may also reflect indirect mechanisms of health selection. One dimension in the indirect process points to individual health related behaviours and attitudes. ${ }^{29}$ Regarding a non-sedentary lifestyle and obesity, a relation might exist between physical functioning and individual work effort and performance. ${ }^{39}$ Behavioural risks, such as a sedentary lifestyle, may influence physical functioning through medical diseases, pre-clinical disease or, independently, via anatomical or physical impairment. Previous research has demonstrated the effect of a sedentary lifestyle ${ }^{40}$ and obesity ${ }^{40}{ }^{41}$ on poor physical functioning. This is an important issue considering physically demanding hospital work. In this study, smoking and alcohol use were not related to future permanent jobs, but their prevalence was low in the cohort, as shown in earlier research on hospital staff. ${ }^{42}$

\section{Job satisfaction and other predictors of selection}

We found that high overall job satisfaction was an antecedent to permanent employment, possibly reflecting the employees' good adjustment to work and their work unit. Similarly, the study of temporary to permanent employees by Bauer and Truxillo $^{14}$ revealed that role adjustment and feelings of acceptance from managers predicted success in being hired permanently.

With regard to the demographic and occupational characteristics, male sex, moderate length of organisational tenure, salary above the median, and full time work predicted permanent employment. These results correspond to the study of Roberts et al, ${ }^{43}$ in which upward occupational mobility in the British Civil Service population was higher for men and for employees at the higher educational and occupational levels than for others. Our results indicating a low proportion of part time workers becoming permanent may reflect, on one hand, the disadvantages of part time work for employees, and on the other hand, a voluntary choice of some employees. ${ }^{44}$

High socioeconomic status predicted permanent employment while low status predicted both termination of employment and staying in fixed term employment position. A two way and cumulative process, similar to the relation between health and unemployment, possibly comes into play in the employee mobility between the different parts of the workforce structure. In such a process, a mutual effect emerges between poor health and disadvantageous labour market status; so that employees with poor health may encounter discriminatory practices by employers, leading to inferior occupational status with increased insecurity and other hazards at work. ${ }^{45}{ }^{46}$ This, in turn, may increase health problems. As well, primarily low socioeconomic status of a person may lead to declining health and employment status. ${ }^{47}$ Similarly, for employees with good health and/or high socioeconomic status, a positive process between health and work environment may enhance their resources in "surviving". 


\section{Turnover}

Turnover was not consistently associated with health selection, although we found that among those who were no longer employed by the organisation by the time of follow up were people with high sickness absence rates and dissatisfied workers. No differences were found in self rated health, psychological distress, or lifestyle between the stayers and the leavers, however. In previous research, health selection has proved to operate in the work force mobility from employment to unemployment. ${ }^{5-9}$ Furthermore, employees in lower social positions have proved to be more vulnerable in regard to the impact of poor health on their employment status. ${ }^{9}$ Our results indicated low income and high sickness absence independently as risks of dropping out, but no joint effects of ill health and income were evident. These results may partly be attributable to our inability to distinguish between voluntary leaving and involuntary notice. In future, it would be important to focus on the ways in which the causes and consequences of ill health intersect with other indices of social inequity, perhaps linking the health selection and social causation hypotheses together. ${ }^{29}{ }^{47}$

\section{Conclusions and implications}

In conclusion, we have demonstrated health selection from a new point of view in the labour market-that is, from fixed term employment to permanent employment. Self rated good health and non-sedentary life style remained the strongest predictors of mobility towards permanent employment. The effects of psychological distress and job satisfaction disappeared in the fully adjusted models, but the adjustments of them with intercorrelated variables made them conservative. Psychological health and job satisfaction may be parts of a causal chain reflecting the interplay of health and other aspects of wellbeing. Previously, self rated poor health has been described as a "common feature" linking various adverse psychosocial states such as social isolation, negative life events, depression, job stress, and hostility and suggested to be a proxy to other psychosocial influences. ${ }^{48}$

Selective effects of health, job satisfaction and health behaviour on subsequent employment contract became evident in a group of relatively young, high functioning cohort. From the individual's point of view, the question of social discrimination came up; that is how society, by references to health or related attributes, evaluates particular characteristics and allocates the occupational opportunities accordingly. ${ }^{29}$ People with impaired health may be more vulnerable in critical transitions in their course of life, and this, in turn, reinforces the social gradient in health. This aspect should be taken into account in the formulation of educational and employment policy, and also when searching for measures to reduce socioeconomic differences affecting the health of working populations.

In this study, men and employees with a higher income had the advantage of being permanently employed. Future studies should explore the potential cumulative effect of health, behavioural risks, sex, socioeconomic status, and other potential effects on this form of employment mobility. The present cohort comprised mainly of female healthcare workers; this somewhat limited the generalisability of the results. For example, a male dominated occupation, a low national unemployment rate, and different employment regulations might give different results. The replication of the study in different contexts would be important.

\section{Contributors}

MV with MK and ME formulated the hypothesis and designed, checked and collated the data. MV was the principal author of the paper, providing all the data analyses. $\mathrm{MK}$, the coordinator of the project, ME and JV advised in the interpretation and presentation of the results and co-authored to the writing of the paper.

\section{Policy implications}

- The issue of health selection from less secure job to permanent employment should be considered in the employment policy to reduce the widening of socioeconomic differences in health.

- Breaking of the vicious circle in which job insecurity is both a cause and a consequence of poor health is a great challenge in today's work life.

\section{Authors' affiliations}

M Virtanen, Finnish Institute of Occupational Health, Helsinki, Finland M Kivimäki, Department of Psychology, University of Helsinki, Finland M Elovainio, National Research and Development Centre for Welfare and Health, Helsinki, Finland

J Vahtera, Finnish Institute of Occupational Health, Turku, Finland

Funding: the study was supported by grants from the Academy of Finland (project no 44968), the Finnish Work Environment Fund (project no 97316) and the hospitals in the districts of Varsinais-Suomi and Kanta-Häme, Finland.

Conflicts of interest: none.

\section{REFERENCES}

1 Aronsson G. Influence of worklife on public health. Scand J Work Environ Health 1999;25:597-604.

2 Letorneux V. Precarious employment and working conditions in the European Union. European Foundation for the Improvement of of Living and Working Conditions. Luxembourg: Office for Official Publications of the European Communities, 1997.

3 Robinson JC. Job hazards and job security. J Health Polit Policy Law 1986;11:1-17.

4 Blane DB. An assessment of the Black Report's explanation of health inequalities. Sociol Health Illness 1985;7:423-45.

5 Klein-Hesselink DJ, Spruit IP. The contribution of unemployment to socioeconomic health differences. Int J Epidemiol 1992;21:329-37.

6 Mastekaasa A. Unemployment and health: Selection effects. J Community Appl Soc Psychol 1996;6: 189-205.

7 Ferrie JE. Labour market status, insecurity and health. Journal of Health Psychology 1997;2:373-97.

8 Leino-Arjas P, Liira J, Mutanen P, et al. Predictors and consequences of unemployment among construction workers: prospective cohort study. BM 1999;319:600-5.

9 Bartley M, Owen C. Relation between socioeconomic status, employment and health during economic change, 1973-93. BM 1996:313:445-9.

10 Claussen B, Björndal A, Hjort P. Health and re-employment in a two year follow up of long term unemployed. J Epidemiol Community Health 1993;47: 14-18.

11 Koivusilta L, Rimpelä A, Rimpelä M. Health status: does it predict choice in further education? J Epidemiol Community Health 1995:49:131-8.

12 Van der Lucht F, Groothoff J. Social inequalities and health among children aged 10-11 in the Netherlands: causes and consequences. Soc Sci Med 1995;40:1305-11.

13 Östlin P. Negative health selection into physically light occupations. J Epidemiol Community Health 1988:42:152-6.

14 Baver T, Truxillo D. Temp-to-permanent employees: a longitudinal study of stress and selection success. J Occup Health Psychol 2000;5:337-46.

15 Sutela H, Vänskä J, Notkola V. Pätkätyöt Suomessa 1990-luvulla. [Contingent employment in Finland in 1990s]. Työmarkkinat 1, Helsinki: Tilastokeskus, 2000;67:98

16 Statistics Finland. Tilastotietoa, Suomi lukuina, työelämä, työttömyys, 1998. [Statistics, Finland in Figures, Working life, Unemployment, 1998]. http://www.stat.fi/tk/tp/tasku/taskut/en.html. Searched'12 April, 2001.

17 Blaxter M. Evidence on inequality in health from a national survey. Lancet 1987; ii:30-3.

18 Idler EL, Angel RJ. Self-rated health and mortality in the NHANES-I Epidemiologic Follow-up Study. Am J Public Health 1990;80:446-52.

19 Marmot MG, Davey Smith G, Stansfeld S et al. Health inequalities among British civil servants: the Whitehall II study. Lancet 1991;337:1387-93.

20 Vahtera J, Pentti J, Uutela A. The effect of objective job demands on registered sickness absence spells; do personal, social and job-related resources act as moderators? Work Stress 1996;10:286-308.

21 Vahtera J, Kivimäki M, Pentti J. Effect of organisational downsizing on health of employees. Lancet 1997;350:1124-8.

22 Kivimäki M, Vahtera J, Pentti J, et al. Factors underlying the effect of organisational downsizing on health of employees: longitudinal cohor study. BM 2000;320:971-5.

23 Goldberg DP. The detection of psychiatric illness by questionnaire. Maudsley monograph no 21. London: Oxford University Press, 1972. 
24 El-Rufaie OF, Daradkeh TH. Validation of the Arabic version of the thirty- and twelve-item General Health Questionnaires in primary care patients. Br J Psychiatry 1996;169:662-4.

25 Goldberg DP, Gater R, Sartorius N, et al. The validity of the two versions of the GHQ in the WHO study of mental illness in general health care. Psychol Med 1997;27:191-7.

26 Hackman JR, Oldham GR. Development of the Job Diagnostic Survey. J Appl Psychol 1975;60: 159-70.

27 Kaprio J, Koskenvuo M, Langinvainio $\mathrm{H}$, et al. Genetic influences on use and abuse of alcohol: a study of 5638 adult Finnish twin brothers. Alcohol Clin Exp Res 1987;11:349-56.

28 Kujala UM, Kaprio J, Sarna S, et al. Relationship of leisure-time physical activity and mortality. JAMA 1998;279:440-4.

29 West P. Rethinking the health selection explanation for health inequalities. Soc Sci Med 1991;32:373-84.

30 Rosenblatt Z, Ruvio A. A test of a multidimensional model of job insecurity: the case of Israeli teachers. Journal of Organizational Behaviour 1996;17:587-605.

31 Kinnunen U, Mauno S, Nätti J, et al. Perceived job insecurity: a longitudinal study among Finnish employees. European Journal of Work and Organizational Psychology 1999;8:243-60.

32 Marmot MG. Job insecurity in a broader social and health context. In: Ferrie JE, Marmot MG, Griffits J, et al, eds. Labour market changes and job insecurity. A challenge for social welfare and health promotion. Copenhagen: WHO Regional Publications, 1999:1-9.

33 Joelson L, Wahlquist L. The psychological meaning of job insecurity and job loss: Results of a longitudinal study. Soc Sci Med 1987;25:179-82.

34 Woodward CA, Shannon HS, Cunningham C, et al. The impact of re-engineering and other cost reduction strategies on the staff of a large teaching hospital. A longitudinal study. Med Care 1999:37:556-69.

35 Ferrie JE, Shipley M, Marmot MG, et al. Health effects of anticipation of job change and non-employment: longitudinal data from the Whitehall II study. BM 1995;311:1264-9.

36 Heaney CA, Israel BA, House JS. Chronic job insecurity among automobile workers: effects on job satisfaction and health. Soc Sci Med 1994;38:1431-7.
37 Beale N, Nethercott S. Certificated sickness absence in industrial employees threatened with redundancy. BM 1988;296:1508-10.

38 Kivimäki M, Vahtera J, Thomson L, et al. Psychosocial factors predicting employee sickness absence during economic decline. J Appl Psychol 1997;82:858-72.

39 Chirikos, TN. The relationship between health and labor market status. Annu Rev Public Health 1993;14:293-312.

40 Stafford M, Hemingway H, Marmot M. Current obesity, steady weight change and weight fluctuation as predictors of physical functioning in middle aged office workers: the Whitehall II study. Int J Obesity 1998;22:23-31.

41 Stafford $M$, Hemingway $H$, Stansfeld SA, et al. Behavioural and biological correlates of physical functioning in middle aged office workers: the UK Whitehall II study. J Epidemiol Community Health 1998;52:353-8.

42 Kivimäki M, Elovainio M, Vahtera J. Workplace bullying and sickness absence in hospital staff. Occup Environ Med 2000;57:656-60.

43 Roberts R, Brunner E, White I, et al. Gender differences in occupational mobility and structure of employment in the British Civil Service. Soc Sci Med 1993:37:1415-25.

44 Bielenski H. New patterns of employment in Europe. In: Ferrie JE, Marmot MG, Griffits J, et al, eds. Labour market changes and job insecurity. A challenge for social welfare and health promotion. Copenhagen: WHO Regional Publications, 1999: 11-30.

45 Bartley M. Unemployment and health: selection or causation - a false antithesis? Sociol Health Illness 1988;10:41-67.

46 Bartley M. Unemployment and ill health: understanding the relationship. J Epidemiol Community Health 1994;48:333-7

47 Power C. Social and economic background and class inequalities in health among young adults. Soc Sci Med 1991;32:411-17.

48 Kaplan G, Camacho T. Perceived health and mortality: a nine-year follow-up of the human population laboratory cohort. Am J Epidemiol 1983;117:292-304. 